\title{
Cross-reactions of sera from dogs infected with Angiostrongylus vasorum in commercially available Dirofilaria immitis test kits
}

\author{
Manuela Schnyder ${ }^{*}$ and Peter Deplazes
}

\begin{abstract}
Background: Dirofilaria immitis and Angiostrongylus vasorum are both important potentially fatal canine nematodes with overlapping endemic areas, especially in Europe. The preadult and adult stages of both species are living in the Arteria pulmonalis and the right heart, and diagnostically detectable circulating parasite antigens have been demonstrated for both species. For the detection of D. immitis infections, a variety of commercial tests have been developed, however, they have not been evaluated for cross-reactions against circulating antigens of $A$. vasorum.

Methods: In this study, potential cross-reactions of sera from 16 dogs, which were experimentally infected with $A$. vasorum and which had circulating antigens as confirmed by a species-specific ELISA, were evaluated for the detection of $A$. vasorum antigen in six commercially available D. immitis test kits.

Results: In three fast tests (Witness ${ }^{\circledR}$ Dirofilaria, SensPERT ${ }^{\circledR}$ Canine Heartworm, SNAP ${ }^{\circledR}$ 4Dx ${ }^{\circledR}$ Plus), all sera were negative. One fast membrane ELISA (SNAP ${ }^{\circledR}$ HTWM RT Test) was positive with four sera (25\%), and one serum delivered a non-valid result twice. In the PetChek ${ }^{\circledR}$ HTWM PF Test, depending on the interpretation protocol, 5 or 8 dogs $\left(31.2\right.$ - 50\%) were positive. With the DiroCHEK ${ }^{\circledR}$-ELISA, a single A. vasorum-infected dog (6.2\%) tested positive.

Conclusions: Due to potential cross-reactions with A. vasorum in commercially available test kits for the detection of $D$. immitis antigen, the simultaneous use of highly specific diagnostic methods for the differentiation of these two canine heart worms is recommended.
\end{abstract}

Keywords: Angiostrongylus vasorum, Dirofilaria immitis, Antigen detection, Cross-reactions, Dogs

\section{Background}

The adult stages of Dirofilaria immitis, a filarial nematode, and Angiostrongylus vasorum, a metastrongylid nematode, are both localized in the Arteria pulmonalis and the right heart of their definitive hosts. Dogs, foxes and some other carnivores are the definitive hosts of both parasites, while Culicidae and Gastropoda are the intermediate hosts of $D$. immitis and A. vasorum, respectively.

In Europe, D. immitis is present in coastal Mediterranean areas with expansion northwards, while in North America the parasite has expanded from the southeastern coastal areas northwards and westwards [1] up to Canada [2]. A. vasorum was diagnosed for the first

\footnotetext{
* Correspondence: manuela.schnyder@uzh.ch

Institute of Parasitology, Vetsuisse Faculty, Winterthurerstrasse 266a, 8057, Zürich, Switzerland
}

\section{Biomed Central}

time in France in 1913 [3], but it is only recently that this parasite has regained attention within the veterinary community $[4,5]$. Its presence has been increasingly reported from several new areas in and outside Europe (reviewed in [6]). Reports of an increasing number of cases of canine angiostrongylosis, as well as the development of new diagnostic tools such as ELISAs [7-10] or biomolecular techniques [11,12] may have contributed and also incentivised epidemiological studies, confirming the presence of this parasite in dogs, foxes and snails throughout Europe. The Atlantic provinces of Newfoundland and Labrador are the only regions actually affected by $A$. vasorum in North America, with a potential for expansion to further regions $[4,13,14]$. Overlapping areas in large parts of southern Europe with the presence of both $A$. vasorum and D. immitis have therefore to be accounted for. Furthermore, in non-endemic 
areas of $D$. immitis, this agent has to be considered based on anamnestic information (travelling with pet dogs or imports) and differentiated from A. vasorum infections.

Fatal clinical consequences of $D$. immitis infection are usually prevented by the monthly use of macrocyclic lactones in known endemic areas [15-17], and treatment of dirofilariosis is based on the intramuscular application of the arsenic derivate melarsomine [18] and/or, alternatively, by eliminating the endosymbiont Wolbachia with doxycycline supported by administration of macrocyclic lactones [19]. Dogs infected with A. vasorum, instead, are treated using macrocyclic lactones such as moxidectin [20] or milbemycin-oxime [13], or applying fenbendazole [21]. Prophylactic treatment (with macrocyclic lactones) against potentially fatal canine angiostrongylosis is, as for dirofilariosis, recommended in highly endemic and well known areas [20].

The currently used diagnostic laboratory methods for the detection of these parasites are divergent. The diagnosis of D. immitis is based on the detection of microfilariae or circulating antigens released by mature adult female worms into the blood circulation, both being detectable starting from 6 months after infection [18]. A variety of tests have been developed for the detection of circulating antigens, employing lateral flow immunochromatographic techniques, membrane ELISAs or conventional ELISAs [22-24]. Test evaluations showed that the sensitivity of heartworm antigen tests depends on the worm burden, and the sex and age of the parasites [24-28], while the specificity of the kits is regularly indicated to be very high, between $95 \%$ and $100 \%$ $[23,25,26,29,30]$. However, only occasionally were potential cross-reactions evaluated in animals with natural or experimental infections with other helminths, mainly against other filarial nematodes such as Dipetalonema reconditum [22,31] or Dirofilaria repens, indicating that modern test kits may overcome cross-reactions detected in previously developed test kits for these parasites $[32,33]$, and, rarely, against intestinal parasites such as Ancylostoma caninum and Trichuris spp. [22,34]. The most current diagnostic method for detection of $A$. vasorum infections in dogs is the isolation of first stage larvae (L1) from faecal samples, which are produced by the parasites approximately 6-7 weeks after infection. Larval migration techniques such as the BaermannWetzel method [35] are commonly adopted. Furthermore, ELISAs for the detection of antibodies against $A$. vasorum have been described [7,9], and, recently, tests for the detection of circulating antigen of A. vasorum have been developed. These latter ones have been evaluated for cross-reactions against Crenosoma vulpis $[8,10]$ and also against intestinal parasites (Toxocara canis,
Ancylostoma caninum) and, importantly, against $D$. immitis [8], showing a high specificity (94-100\%).

Due to their common localization within the definitive hosts, their considerable size and particularly the well documented production of circulating antigens [31,36], it was argued that antigens of $A$. vasorum and $D$. immitis may share epitopes responsible for potential crossreactions in antigen detection tests. This hypothesis has been confirmed during the development of the ELISA for the detection of circulating antigen for A. vasorum [8].

The aim of the study was to evaluate potential crossreactions of sera from dogs experimentally infected with $A$. vasorum in six different commercially available tests for the detection of $D$. immitis antigen.

\section{Methods}

A total of 16 sera from dogs experimentally inoculated with 200 third stage larvae (L3) of A. vasorum were obtained during previously performed studies $[20,37]$. Infection of dogs was confirmed by positive Baermann-Wetzel analyses [35], by the detection of circulating A. vasorum antigen [8] and by the presence of adult worms at necropsy adopting an established method of reverse lung perfusion [20]. The day of sample collection (between 55 and 356, mean 101) after inoculation (dpi) and the number of detected parasites at necropsy are shown in Table 1 . Worm burdens varied between 10 and 170 adult parasites, with a mean of 66 worms per dog. Dirofilaria immitis infection was excluded based on the fact that the dogs were living in a non-endemic area under controlled experimental conditions, and at necropsy.

All tests were performed blinded with an identity code from 1 to 16 , by veterinarians (fast tests) or by experienced laboratory technicians from the IPZ (ELISAs).

All sera were non-haemolytic, stored at $-20^{\circ} \mathrm{C}$ and tested within 11-40 months after collection. The following test kits were used, adopting the manufacturer's instruction and within the indicated expiry dates:

1) Witness ${ }^{\circledR}$ Dirofilaria, lateral flow (Synbiotics, San Diego, USA)

2) SensPERT ${ }^{\circledR}$ Canine Heartworm, lateral flow (VetAll Laboratories, Kyunggi-Do, South Korea)

3) SNAP ${ }^{\circledR}$ HTWM RT, membrane ELISA (IDEXX Laboratories, Westbrook, USA)

4) $\mathrm{SNAP}^{\circledR} 4 \mathrm{Dx}^{\circledR}$ Plus, membrane ELISA (IDEXX Laboratories, Westbrook, USA)

5) Petchek ${ }^{\circledR}$ HTWM PF Antigen Test , ELISA (IDEXX, Westbrook, USA)

6) DiroCHEK ${ }^{\circledR}$, ELISA (Synbiotics San Diego, USA) 
Table 1 Comparative results of 16 sera from dogs experimentally inoculated with Angiostrongylus vasorum (Av) tested with 6 different diagnostic kits for the detection of $D$. immitis antigen and with an ELISA for detection of $A$. vasorum circulating antigen [8]

\begin{tabular}{|c|c|c|c|c|c|c|c|c|c|c|}
\hline \multirow[t]{2}{*}{ Dog-ID } & \multirow{2}{*}{$\begin{array}{l}\text { Days post } \\
\text { inoculation } \\
\text { (dpi) }\end{array}$} & \multirow{2}{*}{$\begin{array}{l}\text { Worm } \\
\text { burden } \\
(n)\end{array}$} & \multirow{2}{*}{$\begin{array}{c}\text { A. vasorum } \\
\text { antigen detection } \\
\text { (optical density) }^{1}\end{array}$} & \multicolumn{7}{|c|}{ Diagnostic test kits for the detection of Dirofilaria immitis antigen } \\
\hline & & & & Witness $^{\circledR}$ & SensPERT $^{\circledR}$ & $\begin{array}{c}\text { SNAP } \\
\text { HTWM RT }^{\circledR}\end{array}$ & $\begin{array}{c}\text { SNAP }{ }^{\circledR} \\
\text { 4Dx }{ }^{\circledR} \text { Plus }\end{array}$ & $\begin{array}{c}\text { PetChek }^{\circledR} \\
\text { (veterinary }^{(v)} \\
\text { practice } \\
\text { conditions) }\end{array}$ & $\begin{array}{c}\text { PetChek }^{\circledR} \\
\text { (laboratory }^{\text {conditions) }}\end{array}$ & DiroCHEK $^{\circledR}$ \\
\hline Av 1 & 55 & 49 & 1.484 & neg. & neg. & neg. & neg. & neg. & neg. & neg. \\
\hline$A \vee 2$ & 55 & 54 & 1.825 & neg. & neg. & neg. & neg. & neg. & neg. & neg. \\
\hline Av 3 & 55 & 106 & 1.743 & neg. & neg. & neg. & neg. & neg. & neg. & neg. \\
\hline Av 4 & 55 & 129 & 1.400 & neg. & neg. & neg. & neg. & neg. & neg. & neg. \\
\hline Av 5 & 55 & 134 & 1.485 & neg. & neg. & neg. & neg. & neg. & pos. & neg. \\
\hline Av 6 & 59 & 57 & 0.567 & neg. & neg. & neg. & neg. & neg. & neg. & neg. \\
\hline Av 7 & 59 & 98 & 0.657 & neg. & neg. & neg. & neg. & neg. & neg. & neg. \\
\hline$A \vee 8$ & 76 & 32 & 0.263 & neg. & neg. & not valid & neg. & low pos. & pos. & pos. \\
\hline Av 9 & 76 & 42 & 0.520 & neg. & neg. & neg. & neg. & neg. & neg. & neg. \\
\hline Av 10 & 76 & 68 & 1.007 & neg. & neg. & neg. & neg. & neg. & pos. & neg. \\
\hline Av 11 & 90 & 13 & 0.879 & neg. & neg. & neg. & neg. & neg. & pos. & neg. \\
\hline Av 12 & 90 & 30 & 1.069 & neg. & neg. & neg. & neg. & neg. & neg. & neg. \\
\hline$A v 13^{4}$ & 91 & 10 & 1.264 & neg. & neg. & low pos. & neg. & low pos. & pos. & neg. \\
\hline Av $14^{4}$ & 91 & 170 & 1.396 & neg. & neg. & low pos. & neg. & low pos. & pos. & neg. \\
\hline Av 15 & 286 & 36 & 2.007 & neg. & neg. & low pos. & neg. & pos. & pos. & neg. \\
\hline Av 16 & 356 & 24 & 1.357 & neg. & neg. & low pos. & neg. & pos. & pos. & neg. \\
\hline
\end{tabular}

': optical density values read at $405 \mathrm{~nm}$.

2 : SNAP ${ }^{\circledR}$ HTWM RT test differentiates between low positive (low pos.) and positive results.

3: The interpretation of PetChek ${ }^{\circledR}$ results can be done under an "In-clinic"-protocol based on subjective colour evaluation or under the "Laboratory protocol" by measuring the optical densities at $650 \mathrm{~nm}$ and a cut-off calculation based on positive and negative controls.

${ }^{4}: \operatorname{dog} A v 13$ and $A v 14$ were inoculated with 50 and $500 \mathrm{~L} 3$, respectively.

neg.: negative.

pos.: positive.

\section{Results}

Single test results are shown in Table 1 . All tests, with one exception (see Tab. 1, dog Av 8) fulfilled the criteria for test validity based on the results of positive and/or negative controls.

The ELISA for the detection of circulating A. vasorum antigen was highly positive for all experimentally infected dogs, with absorbance values (optical density read at $405 \mathrm{~nm}, \mathrm{OD}$ ) varying between 0.263 and 2.007 (cut-off value: 0.159 , as previously described [8]), with a mean of 1.096 .

In three fast tests $\left(\right.$ Witness ${ }^{\circledR}$, SensPERT ${ }^{\circledR}$, SNAP $^{\circledR}$ $4 \mathrm{Dx}^{\circledR}$ Plus) all sera resulted negative, while in one fast membrane ELISA (SNAP ${ }^{\circledR}$ HTWM RT) four A. vasorum infected dogs were positive for $D$. immitis antigen, and one serum delivered a non-valid result twice. In the PetChek ${ }^{\circledR}$-ELISA two methods for interpretation were adopted: following the instruction for veterinary practitioners based on eye detection, 5 dogs resulted positive for $D$. immitis infection, while following the instructions under laboratory conditions with OD measurements, a total of 8 dogs were seropositive. With the DiroCHEK ${ }^{\circledR}$ ELISA, a single $A$. vasorum infected dog was $D$. immitis seropositive. With one exception (76 dpi), all crossreactions were observed in dogs infected with $A$. vasorum for more than 90 days, with worm burdens varying from $10-170$.

\section{Discussion}

This study provides evidence of false positive reactions in D. immitis antigen detection kits with sera of dogs infected with $A$. vasorum. The two ELISAs for D. immitis detection (PetChek ${ }^{\circledR}$ and DiroCHEK ${ }^{\circledR}$ ) and the membrane ELISA SNAP ${ }^{\circledR}$ HTWM RT showed single crossreactions against $A$. vasorum, which had not been considered so far. In contrast, the adopted ELISA for the detection of circulating $A$. vasorum antigen has been developed evaluating different monoclonal antibodies, which had been selectively chosen based on their absence of cross-reactivity against $D$. immitis circulating antigens, resulting in an overall high specificity [8]. 
Generally, D. immitis antigen tests are considered to be more sensitive than microfilariae concentration methods or other procedures [38]. In particular, the ELISA technology has been shown to be more sensitive than lateral flow immunochromatography [26] for the diagnosis of heartworm infected dogs. Reasons for the occurrence of false negative results with sera of $D$. immitis positive dogs have been discussed in previously performed studies evaluating different $D$. immitis test kits. Low worm burden and low number of female worms have been shown to reduce sensitivity of the tests $[25,26,39]$. However, increased sensitivity may be coupled with lower specificity and, importantly, with potential cross-reactions against $A$. vasorum. An unknown number of dogs with travel anamnesis and testing positive for circulating heartworm antigen may have falsely been diagnosed positive due to $A$. vasorum cross-reactions, and erroneously treated with melarsomine and/or macrocyclic lactones. Therefore, serological results for $D$. immitis should be confirmed or excluded by additional diagnostic tests (Knott's test for microfilariae of D. immitis, or serology or Baermann migration test for L1 of A. vasorum) or diagnostic imaging frequently delivering pathognomonic findings for heart dirofilariosis $[40,41]$ or angiostrongylosis $[42,43]$.

\section{Conclusions}

In this study we confirmed that sera of dogs infected with A. vasorum cross-react in commercially available test kits for the detection of circulating $D$. immitis antigen. The simultaneous use of highly specific diagnostic tools is recommended for epidemiological studies where both heart worm species occur or for individual dogs with a suspected heart worm infection.

\section{Competing interests}

The authors declare that they have no competing interests.

\section{Authors' contributions}

MS participated in the design of the study, collected the samples, carried out the diagnostic assays and drafted the manuscript. PD conceived the study and implemented the draft of the manuscript. Both authors have read and approved the final manuscript.

\section{Acknowledgements}

Authors sincerely thank Christine Sperlich and Vera Kaspar for technical assistance, Dr. Jeongmi Kim (VetAll Laboratories, Korea) for the free provision of the test kits and IDEXX Laboratories for providing of SNAP ${ }^{\circledR} 4 D x^{\circledR}$ Plus test kits.

Received: 26 September 2012 Accepted: 8 November 2012 Published: 13 November 2012

\section{References}

1. Theis JH: Public health aspects of dirofilariasis in the United States. Vet Parasitol 2005, 133(2-3):157-180.

2. Villeneuve A, Goring J, Marcotte L, Overvelde S: Seroprevalence of Borrelia burgdorferi, Anaplasma phagocytophilum, Ehrlichia canis, and Dirofilaria immitis among dogs in Canada. Can Vet J 2011, 52(5):527-530.
3. Capdebielle H: Embolie cérébrale produit par Strongylus vasorum. Rev Vét 1911, 36(68):144-147.

4. Conboy GA: Canine angiostrongylosis: the French heartworm: an emerging threat in North America. Vet Parasitol 2011 , 176(4):382-389.

5. Traversa D, Di Cesare A, Conboy G: Canine and feline cardiopulmonary parasitic nematodes in Europe: emerging and underestimated. Parasit Vectors 2010, 3:62.

6. Koch J, Willesen JL: Canine pulmonary angiostrongylosis: An update. Vet J 2009, 179(3):348-359.

7. Cury MC, Lima WS, Vitor RWA: Enzyme-Linked Immunosorbent Assay (ELISA) for the diagnosis of Angiostrongylus vasorum (Baillet, 1866) infection in dogs. Revue Méd Vét 1996, 147(7):525-530.

8. Schnyder M, Tanner I, Webster P, Barutzki D, Deplazes P: An ELISA for sensitive and specific detection of circulating antigen of Angiostrongylus vasorum in serum samples of naturally and experimentally infected dogs. Vet Parasitol 2011, 179:152-158.

9. Schucan A, Schnyder M, Tanner I, Barutzki D, Traversa D, Deplazes P: Detection of specific antibodies in dogs infected with Angiostrongylus vasorum. Vet Parasitol 2012, 185:216-224.

10. Verzberger-Epshtein I, Markham RJ, Sheppard JA, Stryhn H, Whitney H, Conboy GA: Serologic detection of Angiostrongylus vasorum infection in dogs. Vet Parasitol 2008, 151(1):53-60.

11. Al-Sabi MN, Deplazes P, Webster P, Willesen $J$, Davidson RK, Kapel CM: PCR detection of Angiostrongylus vasorum in faecal samples of dogs and foxes. Parasitol Res 2010, 107:135-140.

12. Jefferies $R$, Morgan ER, Shaw SE: A SYBR green real-time PCR assay for the detection of the nematode Angiostrongylus vasorum in definitive and intermediate hosts. Vet Parasitol 2009, 166(1-2):112-118.

13. Conboy G: Natural infections of Crenosoma vulpis and Angiostrongylus vasorum in dogs in Atlantic Canada and their treatment with milbemycin oxime. Vet Rec 2004, 155(1):16-18.

14. Morgan ER, Jefferies R, Krajewski M, Ward P, Shaw SE: Canine pulmonary angiostrongylosis: the influence of climate on parasite distribution. Parasitol Int 2009, 58(4):406-410.

15. Arther RG, Bowman DD, Slone RL, Travis LE: Imidacloprid plus moxidectin topical solution for the prevention of heartworm disease (Dirofiloria immitis) in dogs. Parasitol Res 2005, 97(Suppl 1):S76-S80.

16. Clemence RG, Sarasola P, Genchi C, Smith DG, Shanks DJ, Jernigan AD, Rowan TG: Efficacy of selamectin in the prevention of adult heartworm (Dirofilaria immitis) infection in dogs in northern Italy. Vet Parasitol 2000, 91(3-4):251-258

17. Genchi C, Rossi L, Cardini G, Kramer LH, Venco L, Casiraghi M, Genchi M, Agostini A: Full season efficacy of moxidectin microsphere sustained release formulation for the prevention of heartworm (Dirofilaria immitis) infection in dogs. Vet Parasitol 2002, 110(1-2):85-91.

18. McCall JW, Genchi C, Kramer LH, Guerrero J, Venco L: Heartworm disease in animals and humans. Adv Parasitol 2008, 66:193-285.

19. Bazzocchi C, Mortarino M, Grandi G, Kramer LH, Genchi C, Bandi C, Genchi M, Sacchi L, McCall JW: Combined ivermectin and doxycycline treatment has microfilaricidal and adulticidal activity against Dirofilaria immitis in experimentally infected dogs. Int J Parasitol 2008, 38(12):1401-1410.

20. Schnyder M, Fahrion A, Ossent P, Kohler L, Webster P, Heine J, Deplazes P: Larvicidal effect of imidacloprid/moxidectin spot-on solution in dogs experimentally inoculated with Angiostrongylus vasorum. Vet Parasitol 2009, 166:326-332

21. Willesen JL, Kristensen AT, Jensen AL, Heine J, Koch J: Efficacy and safety of imidacloprid/moxidectin spot-on solution and fenbendazole in the treatment of dogs naturally infected with Angiostrongylus vasorum (Baillet, 1866). Vet Parasitol 2007, 147(3-4):258-264.

22. Gillis JM, Smith RD, Todd KS Jr: Diagnostic criteria for an enzyme-linked immunosorbent assay for occult heartworm disease: standardization of the test system in naturally exposed dogs. Am J Vet Res 1984, 45(11):2289-2292.

23. Atwell RB, Sheridan AB, Baldock FC: An evaluation of the Dirochek test for detection of Dirofilaria immitis antigen in dogs. Austr Vet J 1988, 65(5):161-162.

24. Lee AC, Bowman DD, Lucio-Forster A, Beall MJ, Liotta JL, Dillon R: Evaluation of a new in-clinic method for the detection of canine heartworm antigen. Vet Parasitol 2011, 177(3-4):387-391. 
25. Atkins CE: Comparison of results of three commercial heartworm antigen test kits in dogs with low heartworm burdens. J Am Vet Med Ass 2003, 222(9):1221-1223.

26. Courtney $\mathrm{CH}$, Zeng Q: Comparison of heartworm antigen test kit performance in dogs having low heartworm burdens. Vet Parasitol 2001, 96(4):317-322.

27. Martini M, Capelli G, Poglayen G, Bertotti F, Turilli C: The validity of some haematological and ELISA methods for the diagnosis of canine heartworm disease. Vet Res Commun 1996, 20(4):331-339.

28. Rawlings CA, Tonelli Q, Lewis RE, Duncan JR: Semiquantitative test for Dirofilaria immitis as a predictor of thromboembolic complications associated with heartworm treatment in dogs. Am J Vet Res 1993, 54(6):914-919.

29. Levine SE, Mossler JA, Woodard BH: Dirofilaria immitis: a zoonosis of clinical concern. South Med J 1980, 73(6):749-750.

30. Martini M, Poglayen G, Capelli G, Roda R: Diagnosis of canine filariosis: relative sensitivity and specificity of some haematological techniques. Angew Parasitol 1991, 32(3):133-136.

31. Weil GJ, Malane MS, Powers KG: Detection of circulating parasite antigens in canine dirofilariasis by counterimmunoelectrophoresis. AmJTrop Med Hyg 1984, 33(3):425-430.

32. Di Sacco B: Valutazioni comparative e problemi nell'uso di diversi kit diagnostici per la filariosi. Veterinaria 1993, 7(2):20-27.

33. Pantchev N, Etzold M, Daugschies A, Dyachenko V: Diagnosis of imported canine filarial infections in Germany 2008-2010. Parasitol Res 2011, 109(Suppl 1):S61-S76.

34. Brunner CJ, Hendrix CM, Blagburn BL, Hanrahan LA: Comparison of serologic tests for detection of antigen in canine heartworm infections. J Am Vet Med Ass 1988, 192(10):1423-1427.

35. Eckert J, Friedhoff KT, Zahner H, Deplazes P (Eds): Lehrbuch der Parasitologie für die Tiermedizin. 2nd edition. Stuttgart: Enke Verlag; 2008.

36. Ehrenberg JP, Tamashiro WK, Scott AL: Dirofilaria immitis: identification and characterization of circulating parasite antigens. Exp Parasitol 1987, 63(2):205-214.

37. Schnyder M, Fahrion A, Riond B, Ossent P, Webster P, Kranjc A, Glaus T, Deplazes P: Clinical, laboratory and pathological findings in dogs experimentally infected with Angiostrongylus vasorum. Parasitol Res 2010 107:1471-1480.

38. Vezzani D, Fontanarrosa MF, Eiras DF: Are antigen test kits efficient for detecting heartworm-infected dogs at the southern distribution limit of the parasite in South America? Preliminary results. Res Vet Sci 2008, 85(1):113-115.

39. Klotins KC, Martin SW, Bonnett BN, Peregrine AS: Canine heartworm testing in Canada: are we being effective? Can Vet J 2000, 41(12):929-937.

40. Lonsky JM, Thrall DE, Lewis RE: Thoracic radiographic abnormalities in 200 dogs with heartworm-induced cor pulmonale. Vet Radiol 1983, 24:120-123.

41. Badertscher RR, Losonsky JM, Paul AJ, Kneller SK: Two-dimensional echocardiography for diagnosis of dirofilariasis in nine dogs. J Am Vet Med Ass 1988, 193(7):843-846.

42. Dennler M, Makara M, Kranjc A, Schnyder M, Ossent P, Deplazes P, Ohlerth $S$, Glaus TM: Thoracic computed tomography findings in dogs experimentally infected with Angiostrongylus vasorum. Vet Radiol Ultrasound 2011, 52(3):289-294.

43. Kranjc A, Schnyder M, Dennler M, Fahrion A, Makara M, Ossent P, Morgan J, Deplazes P, Glaus TM: Pulmonary artery thrombosis in experimental Angiostrongylus vasorum infection does not result in pulmonary hypertension and echocardiographic right ventricular changes. J Vet Int Med 2010, 24:855-862.

doi:10.1186/1756-3305-5-258

Cite this article as: Schnyder and Deplazes: Cross-reactions of sera from dogs infected with Angiostrongylus vasorum in commercially available Dirofilaria immitis test kits. Parasites \& Vectors 2012 5:258.

\section{Submit your next manuscript to BioMed Central and take full advantage of:}

- Convenient online submission

- Thorough peer review

- No space constraints or color figure charges

- Immediate publication on acceptance

- Inclusion in PubMed, CAS, Scopus and Google Scholar

- Research which is freely available for redistribution

Submit your manuscript at www.biomedcentral.com/submit
C Biomed Central 